\title{
INOVAÇÃO: UMA FERRAMENTA ESTRATÉGICA PARA A GESTÃo DE SERVIÇOS DO SETOR SAÚDE
}

\author{
INNOVATION: A TOOL FOR STRATEGIC BUSINESS MANAGEMENT IN \\ HEALTH
}

\section{INNOVACIÓN: UNA HERRAMIENTA ESTRATÉGICA PARA SERVICIOS DE GESTIÓN DEL SECTOR SALUD}

\section{Wagner Cardoso de Pádua Filho}

Instituto Metropolitano de Ensino Superior - IMES

wagnerpaduafilho@hotmail.com

\section{Vinicius Lana Ferreira}

Instituto Metropolitano de Ensino Superior - IMES

\section{Bárbara Bitencourt}

Instituto Metropolitano de Ensino Superior - IMES

Carla Christiane de Souza Braga Pimentel

Instituto Metropolitano de Ensino Superior - IMES

Gabriela Diniz França

Instituto Metropolitano de Ensino Superior - IMES

Marcelo Rocha de Oliveira

Instituto Metropolitano de Ensino Superior - IMES
Submetido em: 03/02/2015

Artigo aceito em: 26/05/2015

\section{RESUMO}

A inovação vem sendo amplamente discutida como uma ferramenta importante para a modernização e o crescimento sustentável das empresas. Existe uma urgente necessidade de se buscar estratégias inovadoras capazes de agregar valor aos clientes, garantindo assim a fidelização dos mesmos no setor da saúde, visto que a competitividade do mercado neste setor tem sido determinante para o enfraquecimento de suas transações. A inovação é normalmente pensada sob a ótica da tecnologia e de produtos. Entretanto, há uma série de outras áreas na empresa onde se pode implementar estratégias inovadoras. Assim, a inovação pode ser abordada da seguinte maneira: 1) Inovações nas pessoas; 2) inovações no processo; 3 ) inovações e marketing; 4) inovação em produtos e serviços; 5) inovação organizacional; e 6) inovação em sustentabilidade. A inovação é ainda classificada em: radical, incremental, aberta, fechada ou distribuída. O conhecimento detalhado das metodologias e aplicabilidades da inovação é de relevância para a sua adoção como ferramenta estratégica de gestão. Avanços na implementação de ações inovadoras no setor de saúde certamente terão impactos positivos nos resultados do setor.

Palavras-chave: Inovação, Gestão em Saúde, Administração Hospitalar, Setor Saúde.

\section{ABSTRACT}

The innovation has been widely discussed as an important tool for modernization and sustainable business growth. There is an urgent need to seek innovative strategies to add value to customers, thus ensuring customer loyalty in the health sector, as the competitiveness of the market in this sector has been crucial to the weakening of their transactions. Innovation is usually thought from the perspective of technology and products. However, there are a number of other areas in the company where you can implement innovative strategies. Thus, innovation can be addressed as follows: 1) Innovations in people; 2) process innovations; 3) innovations and marketing; 4) innovation in products and services; 5) organizational innovation; and 6) innovation in sustainability. Innovation is classified as: radical, incremental, open, closed or distributed. Detailed knowledge 

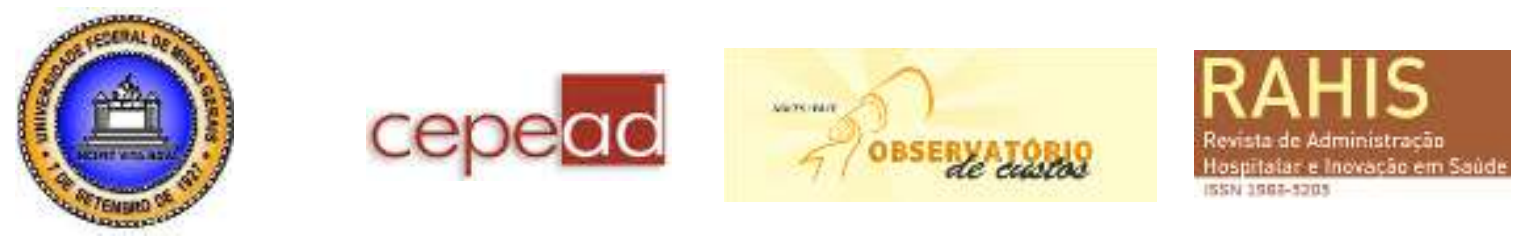

of the methodologies and applicability of innovation is relevant to its adoption as a strategic management tool. Progress in the implementation of innovative actions in the health sector will certainly have positive impacts on industry results.

Keywords: Innovation, Health Management, Hospital Administration.

\section{Resumén}

La innovación ha sido ampliamente discutido como una herramienta importante para la modernización y el crecimiento sostenible de las empresas. Hay una necesidad urgente de buscar estrategias innovadoras para agregar valor a los clientes, garantizando así la lealtad de los clientes en el sector de la salud, ya que la competitividad del mercado en este sector ha sido fundamental en el debilitamiento de sus transacciones. La innovación se suele considerar desde la perspectiva de la tecnología y productos. Sin embargo, hay una serie de otras áreas de la empresa en el que puedan poner en práctica estrategias innovadoras. Por lo tanto, la innovación puede abordarse de la siguiente manera: 1) Las innovaciones en las personas; 2) las innovaciones en el proceso; 3) innovaciones y comercialización; 4) la innovación en productos y servicios; 5) innovación organizativa; y 6) la innovación en sostenibilidad. La innovación es más clasifican en: radical, incremental abierta, cerrada o distribuido. El conocimiento detallado de las metodologías y la aplicabilidad de la innovación es relevante para su adopción como una herramienta de gestión estratégica. El progreso en la implementación de acciones innovadoras en el sector de la salud sin duda tendrá un impacto positivo en los resultados de la industria.

Palabras clave: Innovation, Health Management, Hospital Administration.

\section{INTRODUÇÃO}

A inovação vem sendo amplamente discutida como uma ferramenta importante para a modernização e o crescimento sustentável das empresas. Por isso, inovar no setor de saúde é o maior desafio do momento e só criando novos processos, produtos, serviços e estratégias as empresas poderão reverter este quadro (PÁDUA FILHO; CARVALHO; MEIRA, 2014).

No que se refere à dinâmica da inovação dos serviços, vale notar o papel principal dos hospitais que desempenham atividades mais complexas, pois reúnem os recursos mais especializados e modernos. A despeito dessa importância, os estudos sobre inovação em serviços de saúde de maneira geral e sobre a dinâmica da inovação hospitalar ainda se encontram em fase rudimentar, sugerindo que a área apresenta desafios na busca de novos conhecimentos (BARBOSA; GADELHA, 2012).

As empresas que atuam no setor de saúde no Brasil, principalmente os planos de saúde e os hospitais, vivem, há algum tempo, um cenário desafiador no que se refere ao crescimento, rentabilidade e aumento da base de clientes. O Brasil está apresentando um crescimento econômico robusto nos últimos anos, fruto de um cenário externo favorável e de ações governamentais focadas na distribuição de renda, com forte ascensão social das classes mais pobres da população (PÁDUA FILHO; CARVALHO; MEIRA, 2014).

Apesar da atenção à saúde ser essencial à vida das pessoas e ser considerada necessidade básica de consumo, o setor não tem recebido a maior distribuição de renda na população (PÁDUA FILHO; CARVALHO; MEIRA, 2014).

Algumas razões merecem ser discutidas para tentar esclarecer as possíveis causas para esse fenômeno. Um ponto importante é avaliar o comportamento de compra do consumidor brasileiro. O cidadão com maior poder aquisitivo tende a adquirir produtos e serviços que antes considerados supérfluos ou inatingíveis, na busca de sua satisfação pessoal e seu reconhecimento na sociedade. Na decisão de escolha, ele busca aqueles produtos que ele acredita que podem lhe trazer mais benefícios e vantagens. Este conceito é conhecido por agregação de valor. Alguns produtos e serviços se destacam atualmente, como celulares, 

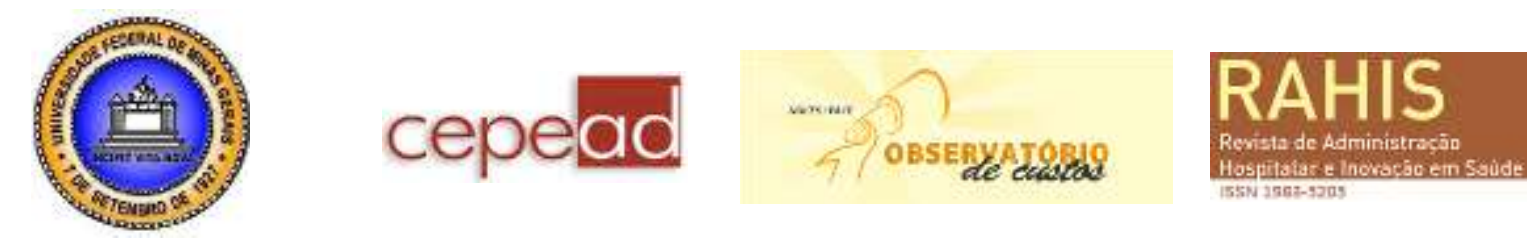

automóveis e viagens. A saúde parece não fazer parte desta lista de prioridades (KRONEMBERGER et al, 2010).

Atualmente, para se obter qualidade, não é suficiente exercer quaisquer atividades da melhor maneira possível. A importância da produtividade cresceu com a globalização, logo, como resultado, é exigido muito mais das pessoas e organizações (BALSANELLI; JERICÓ, 2005).

Um produto ou serviço de qualidade é o que atende perfeitamente, de forma acessível, confiável, segura e no tempo certo, às expectativas do cliente. A busca pela excelência na prestação de serviços aparece como condição essencial nos dias atuais. Atender os anseios dos clientes superando suas expectativas torna-se prioridade para as empresas. Logo, qualidade consiste em alcançar os resultados desejados pela empresa e, ao mesmo tempo, encantar aqueles que consomem seus produtos e/ou serviços (BALSANELLI; JERICÓ, 2005).

Existe uma urgente necessidade de se buscar estratégias inovadoras capazes de agregar valor aos clientes, garantindo assim a fidelização dos mesmos no setor da saúde, visto que a competitividade do mercado neste setor tem sido determinante para o enfraquecimento de suas transações. A relevância do estudo mostra-se por poder compreender e expor novas abordagens relacionadas à inovação no setor saúde.

Os objetivos deste estudo são: analisar as novas estratégias de inovação utilizadas no setor da saúde para agregar valores aos clientes; analisar os problemas atuais enfrentados pelas empresas da área da saúde; citar e conceituar os tipos de inovação, suas aplicações nas empresas e importância de conhecer o comportamento do consumidor; e conhecer as estratégias inovadoras do setor saúde e ressaltar sua importância para fidelização de seus clientes.

\section{DESENVOLVIMENTO}

O conceito de inovação possui diversas definições, encontrando-se entre elas forte concordância. Inovação implica em algo novo para o mercado, na forma de uma tecnologia ou de um modo de organização de atividades econômicas, gerando um produto inédito, uma nova versão de um produto existente ou um processo novo que permita produzir com maior qualidade ou com menores custos um produto já existente (BARBOSA, 2009).

A inovação pode ser definida também como o processo pelo qual as empresas utilizam suas capacidades e seus recursos para desenvolver novos produtos, serviços, sistemas, formas de trabalho e tecnologias para melhor atender às demandas de seus clientes. Pode ser uma prática, política, ou tecnologia, que seja nova para uma organização, mesmo que já seja utilizada por outras (QUEIROZ; ALBUQUERQUE; MALIK, 2013; MAMBRINI et al, 2011).

Inovação foi conceituada também com base em cinco aspectos: 1) introdução de um novo produto ou de uma nova qualidade de um produto; 2) inclusão de um novo método de produção; 3) começo de um novo mercado; 4) aquisição de nova fonte de oferta de matériasprimas ou de produtos semimanufaturados; e 5) criação de uma nova organização para o negócio. A inovação não é invenção, nem descoberta, mas ela pode demandar as duas (MAMBRINI et al, 2011). 

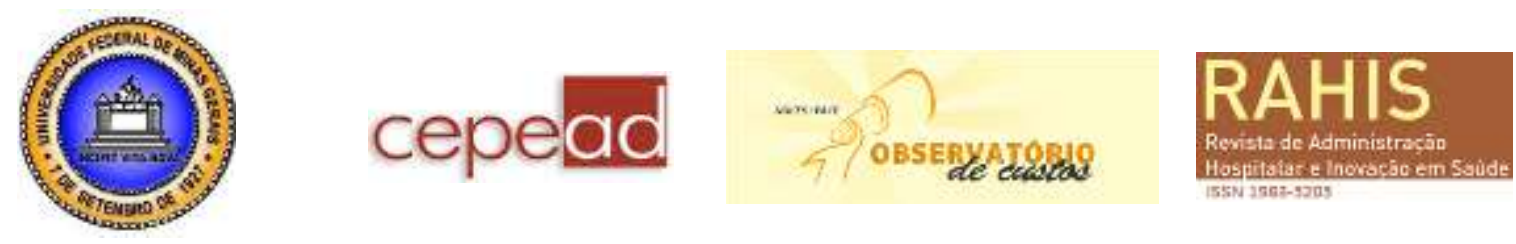

Em função de pressões crescentes do aumento da globalização e da disponibilidade do acesso à tecnologia o tema inovação tem tido presença cada vez maior tanto nas discussões governamentais como nas acadêmicas e nos gabinetes dos executivos corporativos. Devido ao aumento destas pressões e seu impacto na sobrevivência, crescimento e prosperidade das organizações, não deve causar surpresa o fato de que essas organizações busquem uma melhor compreensão dos fatores envolvidos no processo de inovação (BRESSAN, 2013).

Atualmente, o maior desafio que as organizações têm vivenciado para se manterem e se tornarem competitivas frente à globalização e as mudanças constantes, está na sua capacidade de dar respostas rápidas e adequadas a tais mudanças. Nesse cenário de contínuas inovações, agilidade nos processos decisórios e na busca por estratégias focadas na modernização administrativa, também as instituições públicas percebem que têm nas pessoas a sua maior riqueza para se manterem competitivas (CASSINI; TOMASI, 2010).

No Brasil, existe uma preocupação dos setores de saúde público e privado com a incorporação de inovações tecnológicas associadas à área da assistência. Podem-se mencionar, por exemplo, novos medicamentos, mais eficazes; novas técnicas cirúrgicas, que possibilitam intervenções menos invasivas; e procedimentos e medicamentos adequados para atendimento em domicílio, conforme algumas tendências da prestação de serviços (QUEIROZ; ALBUQUERQUE; MALIK, 2013).

Organizações intensivas em conhecimento, como as organizações hospitalares, são embasadas em conhecimentos especializados de seus colaboradores e em tecnologias empregadas em movimento ininterrupto de inovação, com o objetivo de superar os padrões assistenciais atuais. As organizações hospitalares diferenciam-se pela alta complexidade e estão experimentando mudanças significativas na gestão, refletindo o grau de exigência dos clientes, levando a uma modificação nos processos de gestão, criando um novo modo de produção empresarial com atenção voltada para a qualidade dos serviços prestados (TAKAHASHI, 2014).

Entende-se que hospitais especializados, de alta complexidade tecnológica, apresentam condições diferenciadas, reais ou potenciais, para desenvolver inovações nas dimensões institucional, tecnológica e de gestão. Tais inovações iriam surgir a partir de associações com segmentos produtores de bens industriais nas respectivas áreas de atuação. Por isso, é relevante instrumentalizar melhor o entendimento sobre as condições adequadas para os hospitais gerarem inovação (BARBOSA; GADELHA, 2012).

O setor de saúde reúne condições particulares na perspectiva da inovação e do desenvolvimento, permanecendo entre os setores mais dinâmicos em termos de crescimento econômico. Porém, é necessário superar o atual padrão, no qual prevalece uma desarticulação entre os sistemas nacional de saúde e de inovação, manifestada de diversas formas (BARBOSA; GADELHA, 2012).

Para incentivar a qualificação da atuação do Estado, há que se entender melhor como as inovações se dinamizam, e como se estabelecem processos de inovação no âmbito dos serviços de saúde (BARBOSA; GADELHA, 2012).

Os serviços hospitalares, devido à sua complexidade e interação próxima com os diferentes setores econômicos e sociais, podem trazer à tona várias questões teóricas fundamentais no debate sobre inovação em serviços, assim como proporcionar uma nova perspectiva de gestão hospitalar. Como os serviços hospitalares podem inovar? Quem são os 

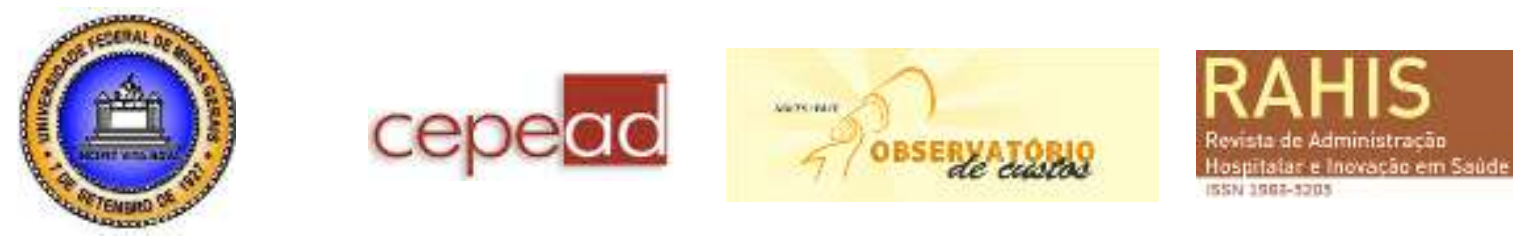

principais agentes dos processos de inovação? Qual é a repercussão de tais inovações na melhoria da saúde, acesso a serviços e qualidade de vida? Existem várias outras questões importantes a serem consideradas, mas esta breve lista já é suficiente para avaliar a complexidade destes serviços e inter-relações que podem ser identificadas através da avaliação do processo de inovação (VARGAS et al, 2014).

A partir da última década, vem se configurando no Brasil um ambiente de estímulo à implantação da cultura da inovação nas empresas ao serem disponibilizados meios de incentivo, entretanto, observa-se ainda que é incipiente o uso desses instrumentos por parte delas. Dessa maneira, cabe às agências públicas de incentivo, a divulgação desses instrumentos, o aperfeiçoamento das estruturas de direcionamento dos recursos para o setor produtivo, no sentido de levar o conhecimento das universidades na direção das empresas inovadoras e garantir que os recursos sejam empregados corretamente de modo a se obter os resultados almejados (MAMBRINI et al, 2011).

Os estudos sobre inovação no setor saúde ainda se encontram em fase inicial, quando comparados a formulações já consagradas na área da manufatura. As pesquisas nacionais brasileiras, sobre inovação, não abordam o tema dos serviços de saúde. Mesmo na Europa, as pesquisas oficiais sobre inovação ainda sofrem críticas por não considerarem de maneira adequada a indústria de serviços (BARBOSA, 2009).

O tema da inovação em saúde mostra então desafios por novos conhecimentos. Além disso, contribuições recentes têm ampliado a necessidade de aprofundamento sobre o papel das inovações em saúde no desenvolvimento econômico. A inovação no setor hospitalar e a partir das relações entre o hospital e agentes externos, é composto por um complexo e pouco estudado processo a gerar dinamismo econômico na cadeia produtiva de saúde (BARBOSA, 2009).

As inovações no campo organizacional e administrativo são mais facilmente reconhecidas, quando estes assumem novas formas, incorporam novas técnicas e metodologias, aprimorando a capacidade gerencial. A dinâmica inovadora através das incorporações tecnológicas, em particular nas tecnologias biomédicas e relacionadas com novos fármacos e medicamentos são igualmente reconhecidas. Entretanto, ainda existe o desafio de melhor compreensão dessa dinâmica, aceitando-a como mais complexa e diversa, mais interativa, além da lógica organizacional-administrativa ou da simples dependência da absorção tecnológica da indústria (BARBOSA, 2009).

Os seguintes aspectos sustentam uma empresa inovadora: 1) o clima e a cultura organizacional; 2) as habilidades e capacidades de gerenciamento; 3) a estrutura e o controle organizacional; e 4) o desenvolvimento de processos e os novos produtos. A inovação contínua está fundamentada nas capacidades e atitudes das pessoas que trabalham na empresa, as quais dependem de uma cultura que estimule o empreendedorismo individual e o trabalho em equipe. Os empresários devem aprender a construir e administrar uma organização inovadora e uma equipe capaz de transformar suas ideias em tecnologia, produtos e processos, de desejar, prever e aceitar o novo (MAMBRINI et al, 2011).

Mas inovar vale a pena? Estudos recentes mostram que empresas que baseiam seus negócios em inovação e propriedade intelectual são mais valorizadas pelo mercado financeiro (PÁDUA FILHO; CARVALHO; MEIRA, 2014). 

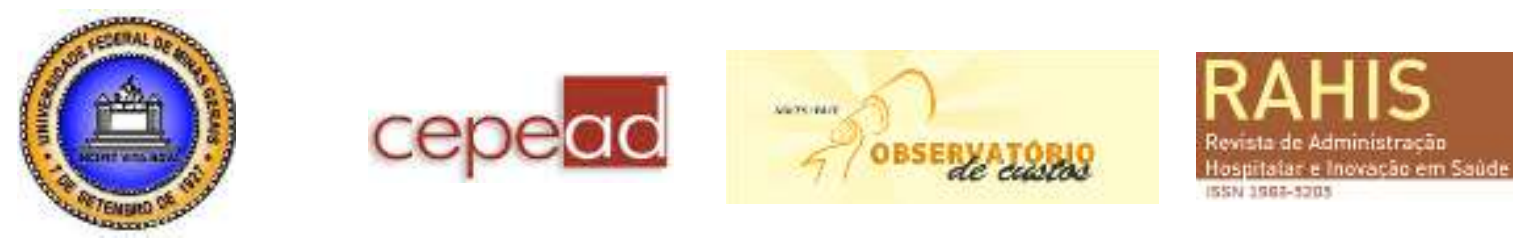

Uma empresa inovadora é aquela que é voltada para a cultura da inovação, estimula a geração de ideias; incentiva o trabalho multidisciplinar, articula seus processos de modo a proporcionar um ambiente favorável à inovação, faz o desenvolvimento contínuo de capital humano (PÁDUA FILHO; CARVALHO; MEIRA, 2014).

\section{VISÃO ESTRATÉGICA DA INOVAÇÃO EM SAÚDE}

Um dos grandes paradigmas sobre inovação ainda presentes no mercado é o que associa inovação com tecnologia e com produtos. Certamente estas são expressões importantes mas é absolutamente necessário desmistificar e ampliar o foco de atuação. Assim, a inovação pode e deve ser pensada estrategicamente em outros setores da empresa:

1. Inovações nas pessoas - relacionam-se a inovações que podem transformar o comportamento ou as crenças das pessoas dentro da empresa, utilizando técnicas como educação e treinamento (QUEIROZ; ALBUQUERQUE; MALIK, 2013). Inclui novos instrumentos para contratar e selecionar colaboradores, desenvolver e aperfeiçoar carreiras, novas metodologias para melhorar a produtividade, o trabalho em equipe, a integração entre vários setores e novas ideias criativas, além da motivação dos funcionários (PÁDUA FILHO; CARVALHO; MEIRA, 2014).

2. Inovações no processo - é baseada na introdução de novos elementos nas atividades da organização, no seu processo de informação ou na produção física ou nas operações de serviços. Demonstram avanços na tecnologia da empresa. As inovações em processos são as adesões de métodos de produção novos ou melhora significativa destes métodos. Eles permitem avanços na produtividade, diminuição de custos, incremento da produção de equipamentos e processos, entre outros. Na gestão das inovações em processos, o sucesso depende da capacidade de desenvolvimento e implementação do processo da contínua inovação incremental. Podem existir avanços significativos, como a instalação de novos equipamentos, automação e informatização de um processo. O sucesso depende do progresso contínuo das mudanças (FONTANINI; CARVALHO, 2005).

3. Inovação em Marketing - a função do marketing na economia de mercado consiste em organizar a troca voluntária de modo a promover o equilíbrio entre oferta e procura de produtos e serviços em situações de múltipla escolha. Tal perspectiva visa a conquista de novos clientes como também relacionamento duradouro com tais clientes e parcerias com outros atores de mercado. Cabe a essa vertente de inovação, investigar, analisar e interagir com as alterações de mercado e ambientais, visando melhoria da qualidade, satisfação do cliente e evolução da empresa (GAMA, 2009).

Alguns desafios enfrentados pelas empresas atuais e que se reportam diretamente à atuação de marketing podem ser citadas tais como: níveis elevados e crescentes de concorrência, substituição de mercados de massa por micromercados e emergência de novos segmentos, sofisticação dos consumidores, globalização de mercado e ritmo acelerado de mudança tecnológica (GAMA, 2009).

O movimento da qualidade total nos anos 80 alterou a ênfase na definição de inovação, introduzindo a ideia de melhoria contínua. A inovação neste sentido genérico de que nada se pode considerar definitivamente acabado e se pode fazer sempre melhor, tanto na perspectiva da eficiência das operações internas, como na da busca de novas e melhores 

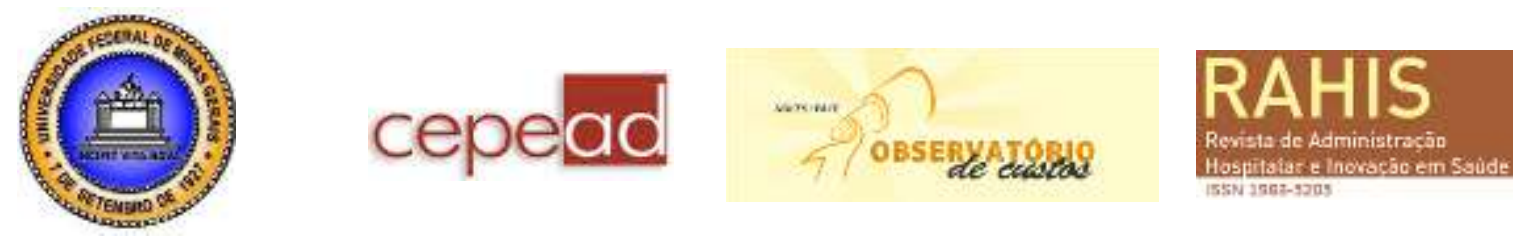

soluções para os problemas dos consumidores, constituem outro marco importante do moderno conceito de marketing (GAMA, 2009).

4. Inovação em Produtos e Serviços - envolvem a introdução de um novo produto ou um serviço que foi substancialmente melhorado. Incluem melhorias em características funcionais, habilidades técnicas, facilidade de uso, com o objetivo de atender constantes mudanças e uma clientela cada vez mais exigente, como também ter seu produto sempre emplacado no mercado em constantes mudanças. Tal inovação requer sempre novas tecnologias, equipamentos, sistemas técnicos e profissionais com alta capacidade criativa. Dessa forma, o setor de serviços seria diretamente dependente de "fornecedores" para inovação. A demanda dos clientes é o quesito mais importante, sendo fonte de informação para adequação do produto, sendo esta relação, serviço - cliente, o "laboratório" onde a inovação é produzida (BARBOSA, 2009).

Os competidores de mercado, obviamente são outro parâmetro para inovação. As indústrias fornecedoras e especialmente baseadas em conhecimentos são importantes fontes de inovação. Cabe ressaltar a importância do setor público como demandador e também fornecedor de pesquisa, educação e regulação para inovação de produtos e serviços (BARBOSA, 2009).

5. Inovação Organizacional - envolve a criação de novas formas de organização nas empresas, práticas de negócios, novos costumes ou ambientes. A inovação organizacional pode ter a intenção de aumentar o desempenho da empresa reduzindo custos administrativos ou custos transacionais, melhorando a satisfação no local de trabalho e dessa forma, a produtividade laboral, ganhando acesso a bens não comercializáveis ou reduzindo os custos dos materiais (DE CASTRO; BASQUES, 2006).

A característica distintiva de uma inovação organizacional comparada com outras alterações organizacionais numa empresa é a implementação de um método organizacional que ainda não foi utilizado por esta antes, isto está ligado enfrentar alterações rápidas e complexas; confrontar-se com ambiguidades; compreender a necessidade de novos produtos e serviços; garantir um sentido de direção em meio ao caos e à vulnerabilidade; e manter a calma diante da perda significativa daquilo que se ajudou a construir (DE CASTRO; BASQUES, 2006).

As primeiras técnicas de mudança organizacional davam ênfase quase somente à estrutura formal da empresa, o que podia significar alterações na hierarquia, bem como a criação, alteração ou extinção de funções. Era necessário também controlar os impactos produzidos com a implantação da mudança. Posteriormente os processos de mudança passaram a enfatizar as pessoas e suas relações, ou seja, o foco do processo passou a ser o comportamento e o clima organizacional, sustentado pelo argumento de que a melhoria das relações e a redução do nível de conflitos influenciam positivamente no desempenho da organização (DE CASTRO; BASQUES, 2006).

$\mathrm{O}$ desafio encontrado à inovação organizacional diz respeito a permitir que organização reaja às demandas do ambiente e à adequação estratégica, possibilitando que seus componentes pessoais, estruturais e tecnológicos permaneçam em harmonia (DE CASTRO; BASQUES, 2006).

6. Inovação em Sustentabilidade - inclui melhorias técnicas de uso de energia, preservação do meio ambiente, diversificação e potencialidades em matérias primas, 
reciclagem de materiais degradáveis ou não (PÁDUA FILHO; CARVALHO; MEIRA, 2014). Organização sustentável é a que simultaneamente procura ser eficiente em termos econômicos, respeitar a capacidade de suporte do meio ambiente e ser instrumento de justiça social, promovendo a inclusão social, a proteção às minorias e grupos vulneráveis, o equilíbrio entre os gêneros, etc (BARBIERI et al, 2010).

Uma organização inovadora sustentável não é a que introduz novidades de qualquer tipo, mas novidades que atendam as múltiplas dimensões da sustentabilidade em bases sistemáticas e colham resultados positivos para ela, para a sociedade e o meio ambiente. Não basta, para as empresas, apenas inovar constantemente, mas inovar considerando as três dimensões da sustentabilidade, a saber: dimensão social - preocupação com os impactos sociais das inovações nas comunidades humanas dentro e fora da organização (desemprego; exclusão social; pobreza; diversidade organizacional etc.); dimensão ambiental - preocupação com os impactos ambientais pelo uso de recursos naturais e pelas emissões de poluentes; dimensão econômica - preocupação com a eficiência econômica, sem a qual elas não se perpetuariam. Tais requisitos requerem das empresas maior esforço para se adequarem a esse novo modelo de gestão associado à sustentabilidade. É o ponto mais difícil das inovações atuais, pois os efeitos sociais e ambientais, a contrário dos efeitos econômicos, são mais difíceis de serem avaliados previamente por envolverem muito mais variáveis, incertezas e interações (BARBIERI et al, 2010).

O modelo de organização inovadora sustentável é uma resposta às pressões institucionais por uma organização que seja capaz de inovar com eficiência em termos econômicos, mas com responsabilidade social e ambiental. Esse tipo de organização busca vantagem competitiva desenvolvendo produtos, serviços, processos e negócios, novos ou modificados, com base nas dimensões social, ambiental e econômica. Ela reúne duas características essenciais: é inovadora e orientada para a sustentabilidade. O modelo das organizações inovadoras sustentáveis vem ganhando rapidamente cada vez mais espaço na atualidade e com perspectivas de perpetuar-se por longos períodos. Desse modo, o aprimoramento dos modelos de organização sustentável, as diversas formas da sua institucionalização em âmbito global, o desenvolvimento de tecnologias sustentáveis, a gestão de inovações para o desenvolvimento sustentável, serão temas cada vez mais importantes nos estudos futuros (BARBIERI et al, 2010).

\section{CLASSIFICAÇÕES DA INOVAÇÃO}

\section{Inovação radical}

Uma inovação radical em serviços pode ser identificada de duas formas. Pode ser expressada por um serviço novo executando função antes inexistente, ou num segundo caso a função seria a mesma, mas sendo executada por serviço que interrompe o serviço antes existente, tendo por base uma nova tecnologia (BARBOSA, 2009).

Um exemplo de inovação radical seria a implantação de um serviço de atenção domiciliar em um hospital, que antes não oferecia este tipo de serviço. Constitui uma nova atividade assistencial, substituindo e acrescentando práticas oferecidas anteriormente apenas no ambiente intra-hospitalar. A atenção domiciliar provoca mudanças no processo de 

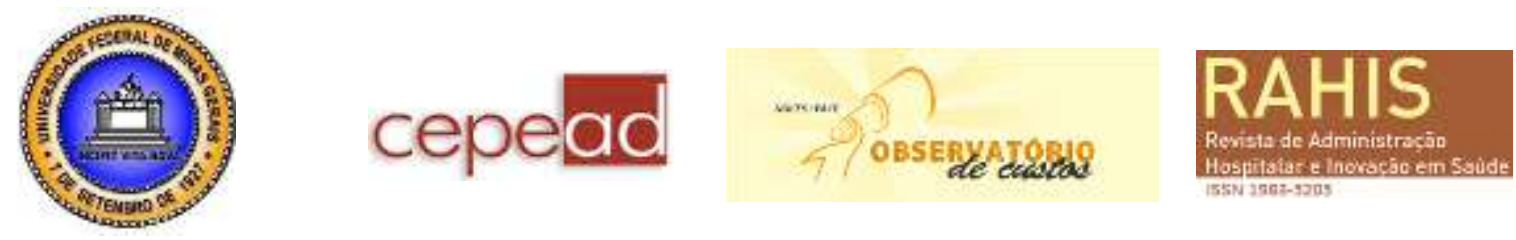

produção hospitalar, modificando radicalmente o ambiente de oferta e a configuração organizacional da instituição. Ela incorpora mudanças tanto para a organização de recursos pelo provedor de serviços, quanto para os clientes. As características do serviço demandam novas competências e ainda, no campo dos agentes externos, ênfase para mudanças radicais tanto para clientes como para os tomadores de decisão. As características dos serviços ao se transformarem em tal relevância o fazem de maneira a interagir com os demais aspectos analíticos, impactando o conjunto dos agentes e das forças que se correlacionam na dinâmica da inovação (BARBOSA, 2009).

\section{Inovação incremental}

As inovações podem ser ainda de caráter incremental, sendo atribuídas à inclusão de qualquer tipo de melhora em um produto, processo ou organização da produção dentro de uma empresa, sem mudança na estrutura industrial. Os exemplos de inovações incrementais são vários, muitos deles não percebidos pelo consumidor, podendo gerar avanço da eficiência técnica, expansão da produtividade, limitação de custos, incremento de qualidade e transformações que possibilitem o aumento das aplicações de um produto ou processo. $\mathrm{O}$ aprimoramento de processos de produção, o design de produtos ou a redução na utilização de materiais e componentes na produção de um produto podem ser considerados inovações incrementais (LASTRES; ABAGLI, 1999).

A inovação incremental pode ser caracterizada como pequenas mudanças nos produtos as quais aumentam sua qualidade e produtividade. A maior parte das inovações são incrementais, com foco no produto e se mostram como uma extensão ou modificação dos produtos existentes. As inovações incrementais não requerem uma interrupção com os negócios existentes e são fundamentadas em competências internas da organização (FONTANINI, 2005).

Quando o foco é no processo a inovação incremental pode ser uma transformação gradual e contínua no processo industrial. Assim, os insumos e os produtos permanecem aparentemente sem modificação e as mudanças ocorrem principalmente dentro dos processos (FONTANINI, 2005).

A inovação incremental pode melhorar a produtividade funcional de processos que utilizam certa tecnologia. Isso acontece devido a aperfeiçoamentos do desempenho, da segurança, da qualidade ou da redução de gastos nesses processos (FONTANINI, 2005).

\section{Inovação aberta}

Inovação aberta parte do princípio de que seus processos precisam de colaboração complementar de diversos atores para tornarem-se científica e tecnologicamente prudentes e comercialmente viáveis. Dessa maneira, a inovação aberta usa fontes de ideias externas à empresa para incrementar a competitividade na geração de novas tecnologias e na busca de resultados (MAMBRINI ET AL, 2011).

A inovação aberta não exclui a importância de continuidade da competência interna para assimilar e adaptar o conhecimento adquirido externamente e, portanto, para agregar seu valor (MAMBRINI ET AL, 2011). 

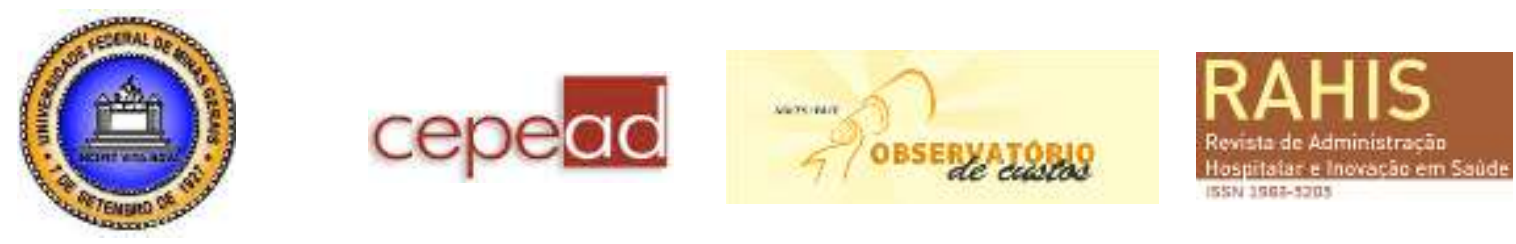

Os modelos abertos, fundamentados na assistência de grande número de atores, acarretam em estruturas de planejamento e gestão mais complexas do que aquelas empregadas até o surgimento dessas novas formas organizacionais. Para que a inovação aberta aconteça de maneira natural, é necessário que uma cultura inovadora seja implementada na empresa (MAMBRINI ET AL, 2011).

Inovação aberta pode ser conceituada como o uso intencional dos fluxos internos e externos de conhecimento para agilizar a inovação interna e a expansão de mercado para uso externo das inovações (TRENTINI, ET AL, 2012).

A inovação aberta indica que os resultados sejam alcançados em ações como a prospecção, análise e exposição de oportunidades de inovação, usando tanto ideias internas como externas para alcançar o mercado. Nesse conceito, outras organizações capazes de internalizar as tecnologias desenvolvidas, podem licenciá-las, criando uma condição em que todos tiram vantagens. A organização pode ainda licenciar tecnologias desenvolvidas por outras organizações ou laboratórios de pesquisa. $\mathrm{Na}$ inovação aberta as ideias, projetos e tecnologias não ficam sem utilização na empresa, pois existe uma interação crescente com fontes externas e com o mercado, incrementando a comercialização e a exploração econômica das mesmas. Dentre os benefícios da inovação aberta, destaca-se a ampliação do alcance e capacidade para gerar novas ideias e tecnologias; a capacidade de desenvolver pesquisas estratégicas com nível de risco inferior e mínimos recursos; a possibilidade de aumento e/ou diversificação do negócio, criando-se novos recursos para crescimento; e a potencialização do retorno sobre os investimentos em pesquisa e desenvolvimento. Nesse modelo as empresas podem comercializar tecnologias internas ou externas e usam recursos internos ou externos no desempenho de projetos (TRENTINI, ET AL, 2012).

\section{Inovação fechada}

No modelo tradicional de inovação fechada os projetos estão idealizados na base científica e tecnológica da empresa, passam por uma escolha interna e alguns são interrompidos enquanto outros recebem mais investimentos sendo que poucos chegam ao mercado. Esses procedimentos são chamados de fechados porque têm somente uma entrada e uma saída. As organizações que trabalham com inovação fechada estão fundamentadas na filosofia de que uma inovação de sucesso tem que ser controlada e as organizações devem desenvolver suas próprias ideias que serão então fabricadas, comercializadas e protegidas (TRENTINI, ET AL, 2012).

\section{Inovação distribuída}

Nas empresas a infraestrutura da informação tem papel cada vez mais vital para a agregação de valor e desenvolvimento de redes de inovação. As transformações de um tipo de configuração para outro são uma ascensão tecnológica e um desafio de domínio e coordenação. Outro enorme desafio é a carência de manutenção da flexibilidade e da permanência na concepção e evolução dessas redes. Nesse contexto, outra definição atual no campo da inovação aberta, é a inovação distribuída. A inovação distribuída é feita ao redor de um bem comum, com a participação de várias pessoas, e por diversas vezes de maneira 

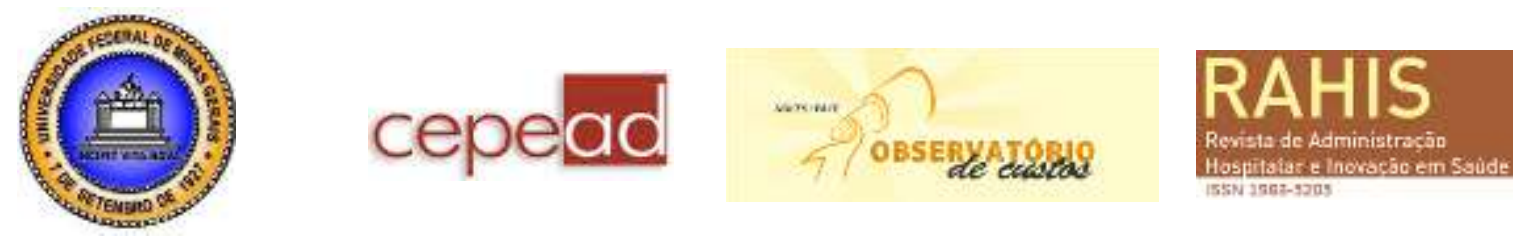

voluntária. A inovação distribuída se destaca no que diz respeito à realização de pesquisas com vários pontos de vista, do emprego de ciência com o código aberto, de organizações virtuais, e desenvolvimento de bens inovadores que envolvem terceiros (TRENTINI, ET AL, 2012).

Com o surgimento da internet, o mundo se tornou conectado, facilitando a ocorrência da inovação distribuída. Uma grande quantidade de inovação aparece no mundo, em todas as formas, e de alguma maneira elas se propagam e atingem cada vez mais pessoas. A empresa não impõe um comando centralizado, visto que a inteligência não habita no seu centro, entretanto a inovação reside principalmente na periferia (TRENTINI, ET AL, 2012).

\section{CONCLUSÃO}

Em termos globais a dinâmica de inovação possui importante protagonismo nas políticas nacionais de desenvolvimento. Embora o conhecimento sobre a dinâmica de geração de inovação em saúde continue crescendo, a análise acerca da geração de inovação no âmbito dos serviços de saúde segue ainda pouco documentada e sob influência de paradigmas. Sem aprofundar o conhecimento dos diversos tipo de inovação, permanecerão atrasos e obstáculos a oportunidades para políticas mais modernas e efetivas em termos de saúde e desenvolvimento econômico. Ademais, as peculiaridades das organizações prestadoras de serviços e em particular as hospitalares exigem novos modelos estratégicos capazes de promover os resultados almejados.

O conhecimento detalhado das metodologias e aplicabilidades da inovação é de relevância para a sua adoção como ferramenta estratégica de gestão. Avanços na implementação de ações inovadoras no setor de saúde certamente terão impactos positivos nos resultados do setor.

\section{REFERÊNCIAS}

ALBUQUERQUE, E.M.; SOUZA, S.G.A; BAESSA, A.R.. Pesquisa e Inovação em Saúde: uma discussão a partir da literatura obre a economia da tecnologia. Rev. Ciência \& Saúde Coletiva, v.9, n.2, p.277-294, 2004.

AMIT, R.; ZOTT, C. Creating value through business model innovation, MIT Sloan Management Review. Disponível em: <http://www.management.wharton.upenn.edu/amitresearch/docs/2012/Amit_Creating_Value_Business_Model_I nnovation.pdf.> Acesso em: 26 set. 2014.

BALSANELLI, A. P.; JERICÓ, M. C.. Os reflexos da gestão pela qualidade total em instituições hospitalares brasileiras. Acta Paul Enfermagem, v.18, n. 4, p. 397-402, 2005.

BARBOSA, P. R.. Inovação em serviços de saúde: dimensões analíticas e metodológicas na dinâmica de inovação em hospitais. Tese (Doutorado) Escola Nacional de Saúde Pública Sergio Arouca. Rio de Janeiro. s.n., 2009.

BARBOSA, P. R.; GADELHA, C. A. G.. O papel dos hospitais na dinâmica de inovação em saúde. Rev Saúde Pública; v. 46, suppl. 1, p.68-75, 2012.

BARBIERI, J.C.; et al. Inovação e sustentabilidade: novos modelos e proposições.

Revista de Administração de Empresas, vol. 50, n. 2, abr-jun, 2010. 


\section{cepead}

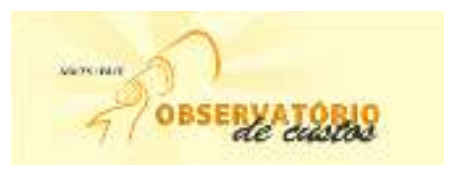

BRESSAN, F. Uma equação proposta para fomentar a inovação nas organizações. Estudios Gerenciales. v. 29, p. 26-36, 2013.

CASSINI, M. R.; TOMASI, A.. O desenvolvimento de uma prática de Gestão do Conhecimento em um Hospital Geral de Belo Horizonte, Brasil. Rev. Portuguesa e Brasileira de Gestão. v. 9, n. 3, 2010.

DE CASTRO, J. M.; BASQUES, P. V.. Mudança e inovação organizacional: estudo de caso em uma empresa do cluster de biotecnologia em Minas Gerais.

Revista de Administração Mackenzie. v. 7, n. 1, p. 71-95, 2006.

FONTANINI, J. I. C.; CARVALHO, H. G. As inovações incrementais em processos e seus fatores contribuintes em um ambiente industrial - um estudo de caso. Disponível em: <http://www.abepro.org.br/biblioteca/enegep2005_enegep0801_1616.pdf> Acesso em: 25 set. 2014.

FONTANINI, J. I. C. Fatores e mecanismos associados à inovação incremental em processos no ambiente industrial: o caso da café Iguaçu. Dissertação (Mestrado) Centro Federal de Educação Tecnológica do Paraná, Unidade de Ponta Grossa. Curso de Pós-graduação em Engenharia de Produção. Ponta Grossa, 2005.

GAMA, A.P; Criatividade e Inovação: Os Novos Desafios do Marketing. Disponível em: <https://infoeuropa.eurocid.pt/registo/000043140> Acesso em: 25 set. 2014.

KRONEMBERGER, A. C.; BICALHO, A. M. S. C.; TEIXEIRA, R. F.; PÁDUA FILHO, W. C.. Marketing em organizações de saúde. 1 ed. Rio de Janeiro: FGV editora, 2010.

LASTRES, H. M. M.; ALBAGLI, S. Informação e globalização na era do conhecimento. Rio de Janeiro: ed Campus, p. 122-128, 1999.

MAMBRINI. A. B. et al. Cultura inovadora na pequena e média empresa. Revista de Gestão e Projetos - GeP, São Paulo, v. 2, n. 1, p 26-51, jan./jun. 2011.

PÁDUA FILHO, W. C.; CARVALHO, C. A. J.; MEIRA, B. M.. Inovação como um desafio para as empresas de saúde: a experiência em hospital privado. RAHIS. Revista de Administração Hospitalar e Inovação em Saúde, v. 11, n.2, p. 58-66 2014.

QUEIROZ, A. C. S.; ALBUQUERQUE, L. G.; MALIK, A. M.. Gestão estratégica de pessoas e inovação: estudos de caso no contexto hospitalar. Revista de Administração, São Paulo, v.48, n.4, p.658-670, out./nov./dez. 2013.

TAKAHASHI, L. B. D. R.. Gestão universitária frente à inovação: estudo empírico no HU/UFSC. Revista de Administração Hospitalar e Inovação em Saúde, v.11 n.3, p. 190-204, 2014.

TRENTINI, A. M. M. ET AL. Inovação aberta e inovação distribuída, modelos diferentes de inovação? R. eletr. estrat. neg., Florianópolis, v.5, n.1, p.88-109, jan./abr. 2012.

VARGAS, E. R.; ET AL. Innovation in hospitals and the service-dominant logic. Revista de Gestão em Sistemas de Saúde-RGSS. v. 3, n. 1, janeiro/junho, 2014. 